\title{
PLANNING AND BUDGET AS A WORK AND PROJECT CONTROL TOOL: CASE STUDY OF THE INTERNAL SYSTEM OF A CENTRAL CONSTRUCTION SITE IN MANAUS
}

\section{Rafael Amilton Leite Colares ${ }^{1}$, David Barbosa de Alencar ${ }^{2}$, Jorge de Almeida Brito Junior ${ }^{3}$, Camily Murrieta Vasconcelos Oliveira Bezerra ${ }^{4}$ and Igor Felipe Oliveira Bezerra ${ }^{5}$}

\author{
${ }^{1,2,3}$ Braulo Cardoso de Mattos Higher Education Institute - FASERRA. Manaus-Amazonas, Brazil. \\ ${ }^{4,5}$ Nilton Lins University. Manaus-Amazonas, Brazil.
} Email: leafar.cad@gmail.com, david002870@ hotmail.com, jorgebritojr@gmail.com, camilymv@ hotmail.com,

Received: Aug $27^{\text {th }}, 2019$

Accepted: Aug 30th 2019

Published: December 02 ${ }^{\text {th }}, 2019$

Copyright (C2016 by authors and Galileo Institute of Technology and Education of the Amazon (ITEGAM).

This work is licensed under the Creative Commons Attribution International License (CC BY 4.0).

https://creativecommons.org/licen ses/by/4.0/

Opea Aceese

\begin{abstract}
Planning is an administrative tool that makes it possible to perceive reality, evaluate paths, build a future framework, structure the appropriate process and reassess the entire process for which it is intended. The budget derives from the management planning process. Planning is therefore the rational side of action. This research presents a study regarding budget errors due to the lack of prior planning through comparative analysis by observing case studies and identifying good procedures to be replicated, and suggesting recommendations to be adopted by organizations that are adopting or intending to adopt a process. Implementation of planning and budget management of works. Among the main errors are the lack of parameterization of budget items and the failure to follow up on field activities. It is up to the engineering professional to pay attention to the correct execution of the monitoring and planning process so that he gets the success of his work.
\end{abstract}

Keywords: Planning, monitoring, control.

\section{INTRODUTION}

With the great competition in the construction sector, construction companies are looking for new technologies that can influence their construction processes, influencing mainly with the increase of productivity, and the reduction of waste in general.

Within this context, studying labor productivity becomes vital to the survival of a construction company. This physical resource represents a significant portion of the total cost and mainly influences the execution time of the works. According to [1], improving labor productivity is a relevant path as its costs represent a significant portion of the total burden on production.

According to [2], important questions must be asked, such as: Can you do it? Is it worth doing? Who does? How to do well? It works?

Without these it is not possible to start a planning that has as its concept the premise of where you want to go, so that it will be defined how it will arrive and what is the most efficient way possible to achieve this goal.
The planning and control process now plays a fundamental role in companies, as it has a strong impact on production performance [3].

With the great need to increase their productivity, as well as increase their competitiveness in the market, construction companies seek to complete their projects in the short term. This is not always a positive factor as it leads to planning and control shortcomings.

Studies to improve productivity in a short time already exist. The fact is to put "planning" into practice, predicting the time and time to complete, provisioning for delays and unforeseen events. Construction companies are detecting some issues that affect the entire process:

Errors in budgets, as they do not foresee the work in its entirety;

Lack of specific planning for completion of works;

Incompatibility with the reality of the market in which the enterprise is located; 
Civil construction that plays an important role in the world economy and has been seeking to rationalize the executive process in general. Cost and quality reduction of the final product must be in accordance with the needs that the market demands.

Through this study we can have a better field of view of the various services performed on the construction site, and can more easily organize the tasks. Well-designed project planning is the fundamental activity for the success of any project, be it infrastructure, education, housing, transportation or industry, both at the competition stage and at the beginning and throughout the construction period. Assuring based on assumptions assumed, a favorable probability with respect to expected results. Through planning, it will be possible to foresee not only the resources needed to achieve the goals set, but also to prevent problems and unforeseen events that may occur.

Planning and control now play a key role in the development of the enterprise. Deficiencies in planning and control are among the main causes of the low productivity of the sector, its high losses and the low quality of its products, but few are the companies in which this process is well structured, that is, they are prepared to meet the needs. Competently meet the competition.

The objective is to present the importance of the planning and monitoring sector within a project, to present technical background on planning works, to analyze the planning system, to analyze the problems caused by the lack of proper planning and to analyze the problems caused by the lack of control in the projects. Construction sites and propose solutions to these failures.

\section{BIBLIOGRAPHIC REFERENCE}

The planning and control process now plays a fundamental role in companies, as it has a strong impact on production performance. Studies conducted in Brazil and abroad prove this fact, indicating that deficiencies in planning and control are among the main causes of the low productivity of the sector, its high losses and the low quality of its products [4].

When planning a work, the manager acquires a high degree of knowledge of the project, allowing greater efficiency in conducting the work. It is difficult to finish a project as planned. Problems, failures and deviations occur during execution. It is not always the culprit that is the organization or company that is executing the project, but external factors are thus beyond the control of management, but can be mitigated with effective planning.

Planning allows us to increase knowledge about the business / project and its market potential.

The main benefits of planning are:

a) Full knowledge of the work: the elaboration of the planning requires the professional to study the projects, the analysis of the construction method, the identification of the productivities provided for in the budget, the determination of the workable period in each front or type of service;

b) Unfavorable Situation Detection: Often, due to lack of planning and control, the construction team fails to take action when the delay is already irreversible. Adopt preventive and corrective measures, and try to minimize impacts on cost and time;

c) Agility of decisions: A planned and controlled work allows a real view of the whole enterprise, making a reliable and agile basis in management decisions;

d) Relationship with the budget: By relating the budget to the planning, it becomes possible to evaluate inadequacies and identify opportunities for improvement;

e) Resource allocation optimization: Allocating resources is studying activity backlash and making important decisions such as analyzing planning, resource leveling, delaying the allocation of certain equipment;

f) Reference for follow-up: The schedule is a very important tool for the follow-up of the work, as it allows a comparison of the predicted as the accomplished;

g) Standardization: planning disciplines and unifies the team's understanding, making the work's attack plan consensual and improving communication;

h) Goal benchmarking: Goal program and deadline bonus can easily be instituted because there is well-built referential planning on which goals can be set;

\section{II.1 PLANNING TYPES}

As the planning of the work is complex and covers its entire duration - which may be months or years - the overall schedule is not a tool for immediate communication with the performing teams. If a work is expected to last for three years, it is impracticable for people to manipulate gigantic schedules on a daily basis, with activities that will only be done one or two years later. Therefore, it appeals to programming, which contains only the set of activities that will be performed over a specific period of time, such as a week or a fortnight [5].

It can be said that programming consists of applying a filter to the overall schedule to show only the activities of a given "window" of time in order to more objectively transfer what should be done in the next week or fortnight. The planner filters out the portion of the entire schedule for a small future period. It is like zooming in on a given time interval.

The programming has the function of being the communication tool of the planning sector with the production sector of the work. The programming serves as the project's agenda, and must be strictly followed. It is recommended that the weekly (or biweekly) meetings of the work be guided by the schedule, as it defines exactly who will do what and what are the expected start and end dates of each activity of that period.

Programming transforms the network of activities into a roadmap for field staff, so that workers and supervisors can perform their tasks within an executive sequence compatible with the overall planning of the work, with a sense of time and a systemic vision of the project.

In short, programming is the translation of global (macro) planning into time-constrained (micro) horizons, with a view to the effective allocation of manpower and equipment, procurement of materials, designation of officers, administrative arrangements, detection of deviations and conducting coordination meetings.

\section{II.2 LONG TERM PROGRAMMING (PLP)}

In long-term programming, the horizons of the plans cover the entire construction period and have as their main objective the definition of the rhythms of the activities which constitute the major stages and their constructive processes of the enterprise.

Planning can be done at various levels of detail and scope, each aimed at one type of decision making and appreciation by different levels of management. As it is intuitive to realize, for the same venture the look of the construction company's board is one, the work manager's is another and the master's is another.

Long-term scheduling consists of the first level of planning detail. It has a more generic character, suited to the highest levels of management (board). Contains few items, usually presented in months. Long-term scheduling (also called the master plan) is basically for the general visualization of the stages of the 
work, explanation of the most important milestones and preliminary identification of resources [6].

For a building, for example, long-term programming would generate a schedule with sub-items:

Preliminary Services; Foundations; Structure; Masonry; Coating.

Due to its remarkably generic character and low degree of detail, long-term programming is not suitable for the daily conduct of the work. Its usefulness is in the visualization of the work as a whole, in the quick identification of the time of operation of each phase of the work, the milestones and the rhythm in which the main production processes should be executed [6].

\section{II.3 MEDIUM TERM SCHEDULE (MTS)}

Second [7], medium-term programming consists of the second level of planning detail. Its basic function is to enable the preparation of a material and equipment purchase plan, identify the need for new resources, train the workforce in a timely manner and anticipate interference. More detailed than the long-term, this schedule serves the site managers well.

Its range is usually between 5 weeks and 3 months, with monthly or biweekly review and update. For the same building as before, the medium term programming would include the following items [7]. floor masonry.

1 floor structure; 2nd floor structure; 1st floor masonry; 2

\section{II.4 SHORT TERM SCHEDULE (STS)}

Short-term scheduling consists of the third level of planning detail. It is the operational-level programming made for field engineers, masters, and contractors. Its scope is weekly or biweekly and its function is to establish clear and immediate guidelines. The short term programming is the "agenda" of the work [3].

According to the aforementioned author, this programming should be done in conjunction with the masters and supervisors and should seek continuity of activities. Surveys conducted in developed countries have shown that the most productive teams are precisely those who devote the most time to understanding and commenting on programming, as they commit more, better manage resources, dialogue with engineers more objectively, in short, acquire a more realistic view. And overall of the work.

The degree of detail of the schedule increases as the activity begins to approach. Short-term scheduling is ideal for identifying the reasons why the tasks of the week were delayed or did not start as planned. This type of programming is the best tool for monitoring the work and providing a "radiograph" of progress continuously.

Also according to previous author, in the foreign literature expression last planner system has been gaining strength to designate the short term plan. The last planners are those in charge and field supervisors who also participate in the planning process, assessing the appropriateness of programming and proposing solutions for interference, conflict and constraints in the field [8].

\section{II.5 PROJECT PHASES}

They are divided into phases containing one or more achievable procedures and verifiable results. These phases are commonly arranged in a logical sequence to ensure greater understanding in the process.
Each phase of management is responsible for a specific outcome that necessarily needs to be achieved for project success.

\section{II.6 PROJECT LIFE CYCLE}

An important and relevant aspect of a project is its life cycle, as, as mentioned in the previous topic, each phase has an activity and, as a project has as characteristics the time for its execution, therefore it necessarily has a certain cycle of life. The life cycle typically defines which techniques will be employed in each phase and who will be involved in performing the tasks in each phase of the project.

Taking an engineering reading, we can understand as project duration, which by definition means the amount of time, in days, weeks, months, hours or minutes, required to perform the activity, ie is the amount of work periods required to perform the activity [8].

Project management can be essentially useful for two types of organizations [9]:

Organizations that base their revenues on projects developed for other companies - architectural, engineering, consulting firms. Public works contractors etc.

. Organizations that adopt project management as a corporate management tool.

For the effective operationalization of project management, information technology is indispensable. Project management information systems are great allies in the planning and control of projects in these organizations. As an example of the benefit of this integrated environment for the company, the highlights include cost and personnel systems. Cost systems can interact with project management systems by assigning cost centers to various departments involved in multiple projects, controlling disbursement and measuring the outcome of capital employed. Personnel systems can be integrated with project management systems, allowing the manager to be able to verify the performance of each individual involved in each of the organization's projects.

Many modern organizations are hybrid structured in functional aspects, respecting the hierarchy and responsibility of their functional managers, but also with project-oriented aspects, where project managers have the exclusive dedication and due authority to perform their duties, especially in critical projects. For important projects. But not so critical, companies present an intermediate variant of organizational structure, the matrix structure. This structure comes in three forms, as in an evolutionary process [9].

\section{II.7 PLANNING AND PRODUCTION CONTROL}

The planning and control of production aims to ensure that a product can be produced or performed a certain service in a way that obtains efficiency and effectiveness in the processes, however, to achieve this it is necessary that the resources and materials considered raw materials are available, meeting the appropriate quality parameters; The activities of the CFP can be divided into: Strategic Level; Tactical level; Operational Level.

At the strategic level, production plans are developed, which are long term for the company's system. At the tactical level, medium-term plans are developed and the Master Production Plan (PMP) is established. At the operational level, short-term programs are prepared, including inventory management, production sequencing and issuance of purchase and production orders at this stage. 


\section{MATERIAL AND METHODS}

For the case study, the monitoring of the elaboration of a system to create a planning of the managerial execution of a project was carried out.

Implementation studies of the quantitative survey system were also carried out to determine the actual input quantities for purchase and use.

For this, processes were developed so that these surveys were standardized within the company.

To enable the receipt of information for budget preparation in other areas of the company, reports were developed with assumptions aligned with those that should be sent via e-mail to those responsible at the beginning of the conception of the work after organizing the folders. The forwarded collections are described below.

\section{STUDY APPLICATION \\ IV.1 PROJECT COST COLLECTION}

List of all projects that are normally contracted for settlement by the Executive Projects team. Forwarded via email shortly after the folder was assembled, with a return date expected at most 10 business days before the budget was completed. When a project is not yet contracted, the responsible area should estimate the cost of its responsibility. If the need for other projects not listed is verified, the Executive Projects area should add them, as well as their respective costs.

\section{IV.2 COLLECTION OF SALARIES AND BENEFITS}

Report with all the functions of the employees of the construction site for the appropriation of salary by the human resources team, as well as the unit cost of all benefits and expenses with occupational health and safety. Forwarded via email shortly after the folder was assembled, with a return date expected at most 10 business days before the budget was completed.

\section{IV.3 IT COST COLLECTION}

It aims to collect quantities and costs of temporary computer facilities at the construction site. Forwarded via email shortly after the folder was assembled, with a return date scheduled for a maximum of 5 business days prior to budget completion.

\section{IV.4 HEAVY EQUIPMENT COST COLLECTION}

Based on the equipment histogram and regionalized price spreadsheet provided by the equipment area, with their respective complementary costs, such as mobilization and demobilization, freight, corrective and preventive maintenance, consumption and productivity, the cost collection will be assembled. In case it is necessary to use equipment not included in the spreadsheet, the report will be sent via e-mail with expected return no later than five business days before completion.

\section{IV.5 INPUT COST COLLECTIONS}

They will be provided by the supply area by making available specific target price spreadsheets for each microregion. Since all purchases made in the company use an Enterprise Resource Planning (ERP), the other unit costs of the inputs are collected through the Purchase Feed Back. Specific items that may not be in the regional catalog or system will be budgeted directly from accredited suppliers.

Calculating quantities is one of the most important steps in the budget process. The surveyor should responsibly observe all criteria, spreadsheets and conferences upon completion to avoid any errors.

The quantity survey must be performed according to the available designs and specifications, using the standard area forms and the CAD (technical design software) tool, always observing the area measurement criteria.

\section{IV.6 SURVEY DIVISION DIAGRAM}

To facilitate understanding of the main subdivisions of the parts of the surveys and, consequently, of the budget spreadsheets, below is a graphical presentation of the most common situations.

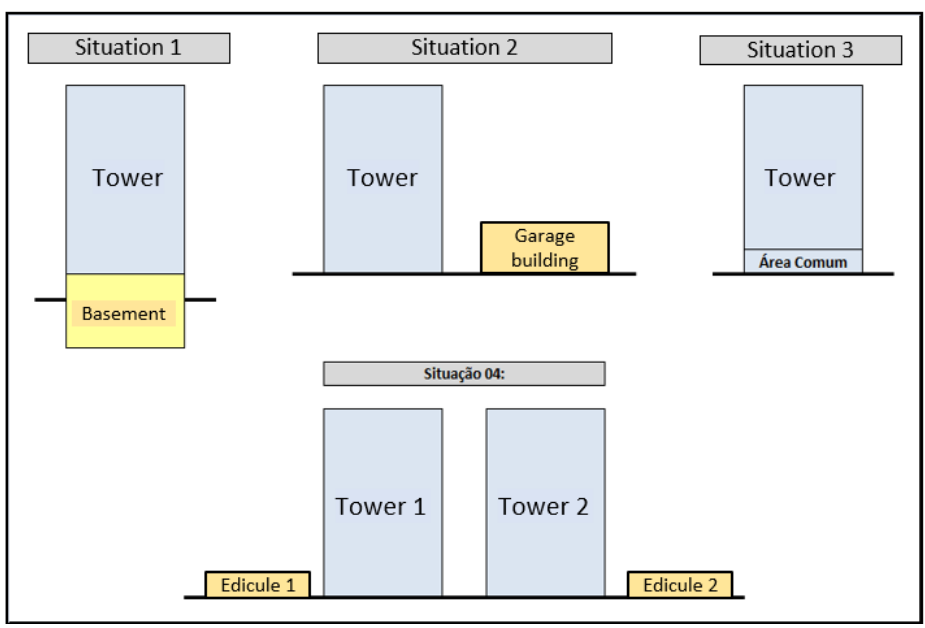

Figure 1: Tower Survey Diagram.

Source: Authors, (2019). situations:

Looking at the diagram, we can see four different

- Situation 01: The surveys will have two sets of spreadsheets: one for the towers and one for the basement;

- Situation 02: The surveys will also have two sets of spreadsheets: one for the towers and one for the garage building;

- Situation 03: The surveys will have a set of spreadsheets, observing the separation of the finishes of the apartments and common area, including the rooms;

- Situation 04: The surveys will have three sets of spreadsheets: one for tower 01 , one for tower 02 , and one for the educts.

\section{IV.7 MEASUREMENT AND SURVEY CRITERIA}

All quantity withdrawals will be in accordance with the measurement criteria below. Services that are not discriminated against can be checked in the "Budget Survey Criteria" document available in the Budget Book. Those not mentioned in this procedure or in the document itself will be performed according to PINI criteria [10].

\section{IV.8 MAIN CRITERIA}

- Masonry: Survey of the elevation area discounting all the spans according to the architectural project;

- External Cladding (Chapisco, Plastering, Plastering, Ceramics and Stones): Only discount spans above $2.00 \mathrm{~m}^{2}$, and 
only those exceeding $2.00 \mathrm{~m}^{2}$ (eg, for $2.52 \mathrm{~m}^{2}$ spans, discount only $\left.0.52 \mathrm{~m}^{2}\right) \mathrm{m}^{2}$ );

- Exterior painting (Acrylic, Latex, Graphite, Textured, etc.): Do not discount window and doorways.

- Interior finishes: Discard all wooden frame gaps and discard any other gaps above $2.00 \mathrm{~m}^{2}$, but only in excess.

- Skirting boards: Discard all doorways.

- Painting wooden doors: Consider the door area multiplied three times ( 2 door faces + frame).
- Painting of metal frames: Consider the area, multiplied

twice.

- Excavation of blocks and straps: If using form, consider the actual width $+40 \mathrm{~cm}$ and the actual length block by block. The depth will be the actual plus five centimeters depending on the execution of the ballast. For executions in which the use of shapes will not be necessary, we will follow the same criterion, but without adding $40 \mathrm{~cm}$ in width.

- Construction lease: The construction perimeter plus 1.50 $\mathrm{m}$ on each edge is considered.

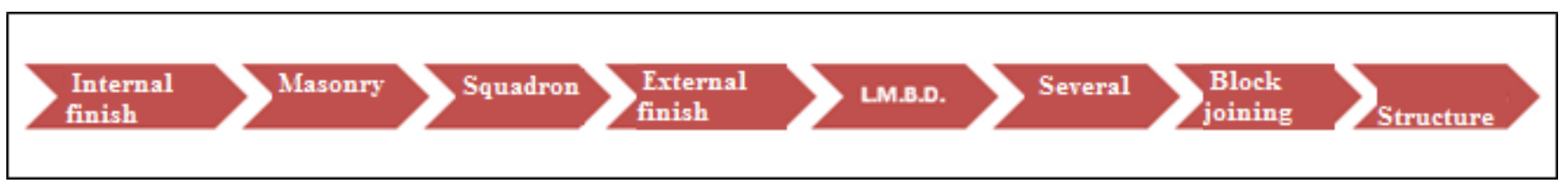

Figure 2: Steps for preparing surveys.

Source: Authors, (2019).

\section{IV.9 ENGINEERING TECHNICAL INDEX COMPARATIVES}

After the quantity survey has been closed, a comparison should be made against standard technical index sheets for preapproval of the respective quantities.

It is important to highlight that this comparative aims at the elaboration of assertive budgets based on the operational efficiency of the company, since the standard indices represent the best practices of accomplished projects.

Remaining the deviations found, the Coordination and Management of the budget area should evaluate the data together with the responsible for the elaboration. The project area should then be informed, and the budget area will proactively indicate the project's poor performance.

\section{IV.10 CRITICAL ANALYSIS AND ABC CURVES}

Standard curves are spreadsheets with the percentage distribution of incidence of inputs or services of works separated by types (horizontal and vertical structural masonry buildings, conventional reinforced concrete structure buildings and concrete wall system), in which a pattern is observed. According to the implementation methodology. In the evaluation stage, the Intelligent $\mathrm{ABC}$ curve should be generated, that is, by accumulating the similar items, verifying, according to the type of project in question, whether the generated percentages are in accordance with the standards. Otherwise, any discrepancies must be justified, or even revised costs and quantities again. A detailed reading of the $\mathrm{ABC}$ Curves for Services, Inputs and Spreadsheets should be made after the budget has been finalized by the Coordinator, asking the responsible person about any distortions of costs and quantities identified. The critical judgment conference may also be held by another budget expert who has not participated in the process, favoring the "impersonality" factor and allowing a second opinion.

\section{RESULTS AND DISCUSSION}

Among the problems encountered due to the failure of planning and management of resources within the enterprise are the lack of control of executive processes.

These processes involve the steps from the receipt of the material to the purchased broom for cleaning the finished apartments.
What often happens is that many contributors believe that the planning and budgeting sector is a mere environment where calculations are made about the work, calculations that do not work.

That is not true. The industry when conducting surveys needs full attention from all service fronts. If you do not get this support, you will:

- Quantitative failures;

- Failures in physical advances;

- Overflow in project costs;

- Lack of process reliability;

- Leftover materials.

When these problems were detected within the enterprise, they required extra attention regarding the execution of a new survey.

All problems related to the failure to perform the survey procedure within the project imply the final value of the work. Over-buying makes the works more expensive, as they will be left with an absurd amount of materials.

In the case of works where there is a large number of repeatability, this failure is even worse, since the error factor is multiplied by the total number of housing units.

\section{FINAL CONSIDERATIONS}

Looking at all the problems encountered by the lack of planning within a venture, it is clear that this process is essential.

The whole organization aims at profitability, good data collection, real results, and for this to be obtained, the monitoring must always be at the side of the execution of the work, with the disposition of the resources employed, demonstration and clarity in the explanation of the indices and data collection for future budgets.

It is the planning that prevents the company, within a construction site, end up spending more than necessary, since it is this procedure that dictates what to do, when to do and how much to spend for this accomplishment, and control is responsible for not let the situation go astray, dictating the rules of resource use and making the appropriate appropriation of general inputs.

Full control of processes and systems ends up bringing many benefits to enterprises in their construction phase. It is known that the amounts invested in the construction of any projects are high, as the inputs commonly employed have high value.

Having the data of the enterprise in hand one can have an overview of the work. The act of planning gives the developer the 
basic notions which are: estimated cost, initial deadline and final deadline for execution. These factors make the building options viable.

\section{REFERENCES}

[1] Araujo, Luís Otávio Cocito de. Método para a proposição de diretrizes para melhoria da produtividade da mão-de-obra na produção de armaduras. 2005. PhD Thesis. Universidade de São Paulo.

[2] Junqueira, Luiz Eduardo Lollato, et al. Aplicação da lean Construction para redução dos custos de produção da casa 1.0®. São Paulo, 2006.

[3] Dórea, Aldo Mattos. Planejamento e controle de obras. São Paulo: Editora Pini, abril 2015.

[4] Dórea, Aldo Mattos, Como preparar Orçamentos de Obras: dicas para orçamentistas, estudos de caso, exemplos. SP, São Paulo. Editora PINI, 2006.

[5] Saurin, Tarcisio Abreu; Formoso, Carlos Torres. Planejamento de canteiros de obra e gestão de processos. ANTAC, 2006.

[6] Silva, Helton Haddad; Tenca, Evandro. Planejamento empresarial. Pós-Graduação Lato Sensu - Tecnologia e Gestão da Produção de Edifícios - MBA-UP/TGP. São Paulo, 2003.

[7] Altounian, C. S. Obras Públicas. Licitação, Contratação,

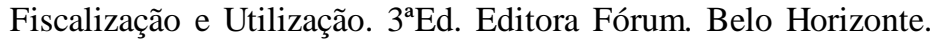
2011.

[8] Camargo, Camila. Planejamento financeiro. Editora Ibpex, 2007.

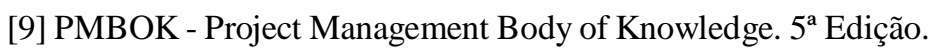
2013.

[10] TCPO - Tabela de Composição de Preços para Orçamentos. Editora Pini. São Paulo. 2013. 